\title{
Revizyon kalça artroplastisinde pelvik devamsızlık
}

\author{
Pelvic discontinuity in revision hip arthroplasty
}

\author{
Kerem Başarır ${ }^{1}$, Hikmet Çetin ${ }^{2}$ \\ ${ }^{1}$ Ankara Üniversitesi Tıp Fakültesi, Ortopedi ve Travmatoloji Ana Bilim Dalı, Ankara \\ ${ }^{2}$ Hakkari Devlet Hastanesi, Ortopedi ve Travmatoloji Kliniği, Hakkari
}

Pelvik devamsızıı, genellikle revizyon total kalça artroplastisi (TKA) sırasında ve bazen de primer TKA sırasında karşılaşılan, asetabular revizyon cerrahisinin zorlu bir komplikasyonudur. Revizyon ve re-revizyon total kalça artroplastileri kompleks cerrahi uygulamalardır. Bu ameliyatlar sırasında cerrahlar, üstesinden gelmeleri gereken birçok zorlukla karşılaşırlar. Pelvik devamsızlığın başarılı bir şekilde yönetilmesinin anahtarı; olguyu dikkatli ve ayrıntılı değerlendirerek, stabil ve dayanıklı bir asetabular komponent yerleştirip, iyileşmeyi sağlamak için uygun ortam oluşturmaktır. Doğru tanı koyup uygun komponentlerin seçimi, komplikasyonları azaltarak iyileşmeyi hızlandıracaktır. Çeşitli tedavi seçeneklerinin sonuçlarını bildiren çok sayıda olgu serisi olmasına rağmen, pelvik devamsızlığın yönetimi, kalça cerrahisinin en zorlu yönlerinden biri olmaya devam etmektedir. Bununla birlikte, tedavi için optimal cerrahi yöntem hâlâ tartışmalıdır. Spesifik cerrahi prosedürlerle tedavi edilen, yeterli hasta serisini içeren uzun vadeli çalışmaların artması, seçilecek tedavi konusunda yol gösterici olacaktır.

Anahtar sözcükler: revizyon kalça artroplastisi; pelvik devamsızık; asetabular kap
Pelvic discontinuity is a challenging complication of acetabular revision surgery, often encountered during revision total hip arthroplasty (THA), and occasionally during primary THA. Revision and re-revision total hip arthroplasties are complex surgical applications. During these surgeries, surgeons face many challenges that they must overcome. The key to successful management of pelvic discontinuity is: to evaluate the case carefully and in detail, to place a stable and durable acetabular component, and to create a suitable environment for healing. Correct diagnosis and selection of appropriate components will reduce complications, and speed up recovery. Despite the large number of case series reporting the outcomes of various treatment options, the management of pelvic discontinuity remains one of the most challenging aspects of hip surgery. However, the optimal surgical method for treatment is still controversial. Increasing number of long-term studies involving adequate series of patients treated with specific surgical procedures will guide the treatment to be chosen.

Key words: revision hip arthroplasty; pelvic discontinuity; asetabular cup

romatoid artrit ve radyoterapi öyküsü, bildirilen risk faktörleri arasındadır. ${ }^{[7,8]}$ Pelvik devamsızlığın başarılı bir şekilde yönetilmesinin anahtarı; olguyu dikkatli ve ayrıntılı değerlendirerek, stabil ve dayanıklı bir asetabular komponent yerleştirip, iyileşmeyi sağlamak için uygun ortam oluşturmaktır. Doğru tanı koyulması ve uygun komponentlerin seçimi, komplikasyonları azaltarak iyileşmeyi hızlandıracaktır.

Her yıl gerçekleştirilen primer TKA işlemlerinin artması sebebiyle, revizyon sıklığı da artmaktadır. Kurtz ve ark., yaptıkları çalışmada, 2030 yılına kadar kalça artroplastisi revizyonlarında \%137 artış olacağını belirtmişlerdir. ${ }^{[9]}$ Gelişen implant teknolojisi ve artan yaşam beklentisi daha fazla hastaya hitap etmeye olanak sağlamıştır. Bununla birlikte, pelvik devamsızlık olgularının da daha yaygın hale gelmesi beklenebilir. ${ }^{[10]}$

İletişim / Contact: Doç. Dr. Kerem Başarır • E-posta / E-mail: basarirkerem@yahoo.com

ORCID iD: Kerem Başarır, 0000-0001-6247-8737 • Hikmet Çetin, 0000-0002-2438-9837 


\section{SINIFLANDIRMA}

Asetabular kemik defektlerini tanımlamak için çeşitli sınıflandırma sistemleri geliştirilmiştir. Amerikan Ortopedi Cerrahları Akademisi (AAOS) ve Paprosky sınıflamaları en yaygın kullanılanlardır. ${ }^{[11]} \mathrm{Bu}$ sınıflamalar asetabular rekonstrüksiyonu planlamaya yardımcı olabilir.

AAOS'nin kalça komitesi tarafından yapılan sınıflamaya göre, Tip IV periasetabular defektler "pelvik devamsızlık" olarak tanımlanmıştır. Yine bu sınıflamaya göre pelvik devamsızlık; hafif veya orta derecede asetabular kemik kaybı varlığında Tip IVA, şiddetli kemik kaybı varlığında Tip IVB, radyoterapi tedavisi sonrası ortaya çıktığında ise Tip IVC olarak alt kategorilere ayrılmıştır. ${ }^{[12]}$

Paprosky ve ark. da, asetabular komponent revizyonu geçiren 147 hastadan oluşan bir seriye dayanan alternatif bir asetabular defekt sınıflandırması önermiş̧lerdir. ${ }^{[13]}$ Antero-superior ve postero-inferior asetabular kolon bütünlügüü temelinde tanımlanan bu sistem, günümüzde en yaygın kullanılan sistemdir. Sistem temel olarak; kalça rotasyon merkezinin superior obturator hatta göre konumuna, iskium ve gözyaşı damlasında osteolizin varlığına ve Köhler (ilioiskial) hattı ile kalça rotasyon merkezinin ilişkisine dayanır. Bu sınıflamaya göre, Tip 3A ve Tip 3B defektler "pelvik devamsızlık" olarak tanımlanmıştır. ${ }^{[13]}$

\section{CERRAHI ÖNCESI DEĞERLENDIRME}

Başarılı klinik sonuçlar için, dikkatli değerlendirme ve ameliyat öncesi planlama yapılması gerekir. Hastaya uygulanmış daha önceki tüm işlemler değerlendirilmelidir. Önceki ameliyat raporlarının temini, implantların özelliği ve boyutları hakkında fikir verecektir. Yumuşak dokunun durumu, önceki kesiler ve abduktor kolun işlevi dikkatli bir şekilde muayene edilmelidir. Ayrıntılı bir nörovasküler muayene yapılmalıdır.

Cerrahi öncesi; beyaz kan hücresi sayımı, eritrosit sedimantasyon hızı ve C-reaktif proteini içeren tetkikler, tüm revizyon hastalarında değerlendirilmelidir. ${ }^{[14]}$ Yüksek olan belirteçler, ameliyat öncesi kalça aspirasyonuna yönlendirmelidir.

\section{Radyolojik Görüntüleme}

Pelvik devamsızlığın tanı ve tedavisinde asetabulumun doğru görüntülenmesi önemlidir. Direkt radyografiler, doğru bir teşhisin temelini oluşturur. Pelvik devamsızlık şüphesi olan tüm hastalar için istenecek radyografiler; pelvis antero-posterior (AP), kalçafemur AP ve lateral kalça grafisidir. Ek olarak, iliak oblik ve obturator oblik görünümleri içeren $45^{\circ}$ oblik Judet grafileri istenebilir. Son zamanlarda yapılan

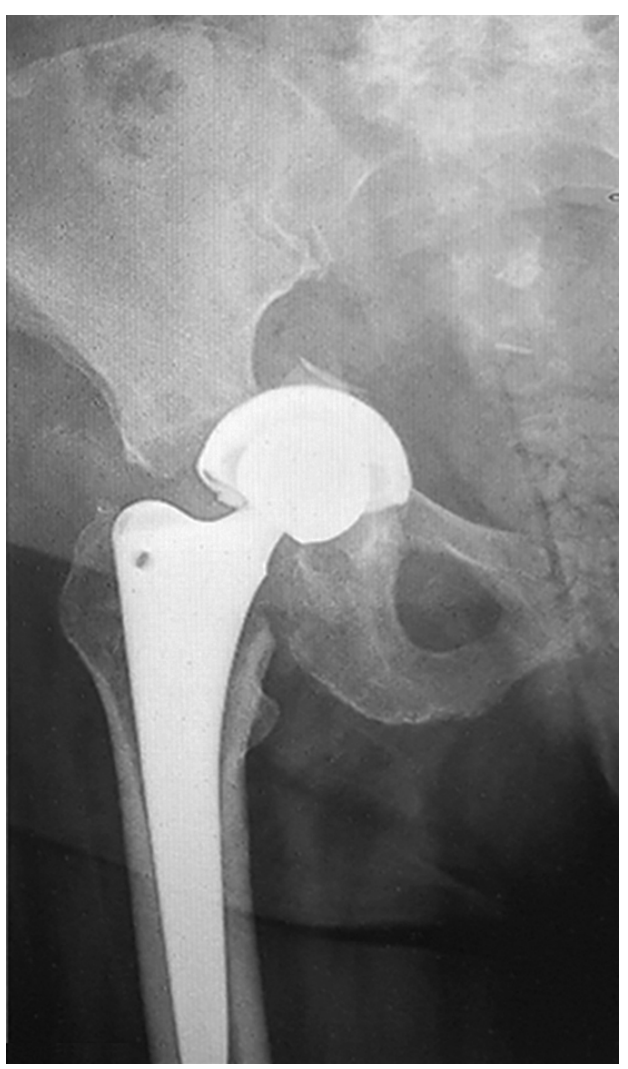

Şekil 1. Antero-posterior (ön-arka) sağ kalça grafisinde asetabular implantın ilioiskial çizgiyi bozarak pelvis içerisine doğru yer değiştirdiği ve pelvik devamlılığın bozulduğu izlenmekte.

bir araştırma, Lequesne (false profile) grafisinin pelvik devamsızlığı tanımlamadaki yararını vurgulamıştır. ${ }^{[15]}$ Martin ve ark., pelvis AP, lateral kalça ve Judet grafilerini içeren kombinasyonun, hastaların büyük bölümünde pelvik devamsızlığın tanımlanmasına yardımcı olduğunu göstermiştir. ${ }^{[16]}$

Pelvis AP radyografisinde; görünür kırık hattı, obturator halka asimetrisi ve Köhler çizgisinin bozulmasıyla hemipelvisin medial migrasyonu, pelvik devamsızlıkla ilişkilendirilmiştir (Şekil 1).

Ek olarak "cross-table" lateral radyografisinin değerlendirilmesi, posterior kolon kırığı olan hastaları belirlemede yararlıdır. ${ }^{[17]}$

Pelvik devamsızlığın değerlendirilmesinde bilgisayarlı tomografi (BT) de yararlıdır. Metal artefaktlar ve kalın kesitler sebebiyle, devamsızlık düzlemini BT ile değerlendirmek zor olabilse de, teknolojik gelişmeler bu sorunların bazılarını azaltmıştır. ${ }^{[18]}$ Özellikle, artefaktların engellenmesi, ince kesitli çekimler ve üç boyutlu yapılandırmalar ile pelvik devamsızlığı değerlendirme daha kolay hale gelmiştir. 


\section{TEDAVI SEÇENEKLERi}

Pelvik devamsızlığın yönetimi, kalça cerrahisinin en zorlu yönlerinden biri olmaya devam etmektedir. ${ }^{[1,19]}$ Bununla birlikte, pelvik devamsızlığın tedavisi için optimal cerrahi yöntem hâlâ tartışmalıdır. Çeşitli tedavi seçeneklerinin sonuçlarını bildiren çok sayıda olgu serisi yayımlanmıştır. ${ }^{[1,20]}$ Spesifik cerrahi prosedürlerle tedavi edilen ve yeterli hasta serisini içeren uzun süreli çalışmalar eksiktir.

Kronik pelvik devamsızlık, tipik olarak zayıf biyoloji ile ilişkilidir; atrofik veya fibröz kaynamamaya benzer şekilde davranır. Pelvik devamsızlığın başarılı şekilde yönetimini etkileyen temel faktörler; kalan kemik stoğu, biyolojik büyüme potansiyeli (biologic ingrowth) ve iyileşme potansiyelidir. Rekonstrüksiyonun ana hedefi, asetabular bileşenin pelvise sert ve dayanıklı (tercihen çimentosuz) tespitini sağlayıp tek bir hemipelvis oluşturmaktır.

Berry ve ark.'na göre pelvik devamsızlı̆̆ın tedavisi[1];

1) sorunun tanımlanması,

2) devamsızlığın stabilizasyonu veya etkili bir şekilde by-pass edilmesi,

3) devamsızlığın olduğu yere uygun şekilde kemik grefti uygulanması,

4) mevcut olan kemik kaybının tedavisi ve

5) stabil bir asetabular implantın yerleştirilmesidir.

\section{Hemisferik Asetabular Komponent ve Açık Redüksiyon - İnternal Fiksasyon}

Posterior kolon kompresyon plağı, görece iyi kemik stoğu olan hastalarda akut pelvik devamsızlık ve bazı durumlarda kronik pelvik devamsızlık için iyi bir tedavi seçeneğidir. Örneğin; primer TKA'da asetabular komponentin yerleştirilmesi sırasında pelvik devamsızlık meydana geldiğinde, plak tespiti ile çimentosuz hemisferik asetabular komponent yerleştirilmesi makul bir tedavi seçeneğidir. Plak tespitinin amacı, defekti kompresyon yoluyla stabil hale getirmek ve kırık iyileşmesini sağlamaktır.

İyileşme potansiyeli, hastanın biyolojisine ve devamsızlığın ameliyat sırasındaki özelliklerine bağlıdır. Otolog iliak krest grefti, devamsızlığın iyileşme olasılığını artırabilir. Bu rekonstrüksiyon formunun amacı, asetabular komponent ve stabil tespit ile biyolojik iyileşmeyi (biologic ingrowth) teşvik etmektir.

Stiehl ve ark., anterior ve/veya posterior plak kullanarak rekonstrüksiyon uyguladıkları 10 hastayı kapsayan serilerinde, altı olguyu çeşitli nedenlerle revize etmişlerdir. Olgularda "bulk" allogreft kullanmışlar ve ortalama 83 aylık takip süresince sekiz hastada devamsızlığın iyileştiğini gözlemişlerdir. Yazarlar, yüksek revizyon oranını hastaların ileri yaşta olmalarına bağlamışlardır (ortalama 68 yaş). ${ }^{21]}$

Berry ve ark., anterior + posterior plak tespiti ve çimentolu bir kap ile tedavi edilen beş hastanın hiçbirinin tatmin edici bir sonuç vermediğini belirtmişlerdir. Aksine, çimentosuz bir soket ve plak tespiti ile rekonstrükte edilen sekiz kalçadan beşinin, son kontrolde mekanik olarak stabil olduğunu belirtmişlerdir. Toplamda, bu sekiz kalçadan dördünde tatmin edici bir sonuç elde edilmiştir. İki olguya tekrarlayan dislokasyon, diğer bir olguya asetabular gevşeme, bir olguya da enfeksiyon nedeni ile revizyon uygulamışlardır. ${ }^{[1]}$

Eggli ve ark., destek kafesi (reinforcement cage) ve her iki kolona plak tespiti ile tedavi ettikleri yedi hastanın klinik sonuçlarını değerlendirmişlerdir. Bir hastanın aseptik implant gevşemesi nedeniyle ek bir revizyon ameliyatı geçirdiğini ve bir başka hastada gevşeyen iki vidanın çıkarılması gerektiğini belirtmişlerdir. Ortalama 96 aylık takipten sonra tüm asetabular bileşenlerin stabil olduğunu; allogreft ve otogreft kullandıkları defektlerin iyileştiğini belirtmişlerdir. ${ }^{[22]}$

Goodman ve ark., plak kullanılmadan sadece kafes ile tedavi edilen 10 olguda \%50 başarısızıı oranı bildirmişler; geniş kavite ve yapısal kemik kaybının olduğu olgularda, kemik grefti ve posterior plak tespitinin hem kaynamaya hem de sistemin stabilitesine yararlı olabileceğini belirtmişlerdir. ${ }^{[23]} \mathrm{Bu}$ çıkarıma ek olarak Roger ve ark., akut pelvik devamsızlık sonrası posterior plak tespiti ve asetabular kap ile rekonstrüksiyon uyguladıkları dokuz hasta içeren serilerinde, 34 aylık takip sonucu revizyon ihtiyacı olmadığını bildirmişlerdir. ${ }^{[19]}$

Springer ve ark., asetabular gevşeme sonrası trabeküler kap ile revizyon yaptıkları yedi olguda ameliyat sonrası dönemde kırık saptamışlardır. Bu olguları, posterior kolona plak tespiti ve greft koyarak revize etmişler, dört olguda iyileşme gözlemişlerdir. Akut kırıkların sebep olduğu pelvik devamsızlık olgularında, plak tespiti uygulaması rekonstrüksiyonun başarısını artıran bir seçenektir. ${ }^{[24]}$

Martin ve ark., posterior kolon plak tespiti ve çimentosuz asetabular kap ile rekonstrüksiyon uyguladıkları 50 hastada yapısal allogreft kullanmışlar ve defektin iyileşme oranını \%74 olarak gözlemlemişler, revizyon gerekmeyen beş yıllık dönemi de $\% 80$ olarak belirtmişlerdir. ${ }^{[25]}$

Pelvik devamsızlıkta plak tespiti, rekonstrüksiyonu daha stabil bir hale getireceği gibi, greft kaynamasını hızlandırarak biyolojik iyileşmeye de katkıda bulunur. Görece geniş bir yaklaşımla uygulanması ve kullanılan implant yükü, kısa ve uzun vadede komplikasyonları artırabilir. Bu konuda spesifik ve daha uzun süreli çalışmalara ihtiyaç vardır. 


\section{Asetabular Distraksiyon}

Sporer ve ark., 2012'de, pelvik devamsızlığı yönetmek için pelvik distraksiyon yöntemini tanımladılar. Bu yöntemde pelvik stabilite, pelvisin elastikiyeti yanı sıra superior ve inferior hemipelvisin "highly porous metal cup/augment" ve vidalarla tespit edilmesi sonrası oluşan distraksiyon ile sağlanır. Defektin üstünde ve altında iyileşme meydana gelene kadar, kap, segmental bir destek olarak işlev görür. Bu da, birleştirilmiş ve stabil bir hemipelvis ile sonuçlanır. ${ }^{[26]}$

Bu teknik; defektte periferal (lateral) distraksiyona ve merkezi (medial) kompresyona izin vermek için ekstra asetabular bir distraktör yerleştirilmesine dayanır. Augmentler, kavite içinde ve dışındaki defektler için kullanılır, daha sonra da çimento aracılığıyla cupa birleștirilir. ${ }^{[26-28]}$

Distraksiyon yöntemi nispeten yakın zamanda tanıtılmıştır; dolayısıyla, bu yöntemle ilgili veriler sınırıdır. Sporer ve ark., bu yöntemle tedavi edilen 20 hastaya ilişkin verilerinde, 15 hastanın ortalama 4,5 yıllık takipte radyografik kap stabilitesine sahip olduklarını belirtmişlerdir. Serideki bir olguda aseptik gevşeme için revizyon gerekmiş, erken dönemde asetabular komponentte migrasyon gelişen dört olgu da klinik olarak asemptomatik ve radyografik olarak stabil seyretmiştir. Ameliyat sonrası dislokasyon olmayan seride, Merle d'Aubigné ve Postel ölçek skorunda önemli iyileşme belirtmişlerdir. ${ }^{26]}$

Sheth ve ark., distraksiyon yöntemi ile tedavi ettikleri 32 hastadan birinde aseptik gevşeme için revizyon gerektiğini, iki hastada ise radyolojik gevşeme belirtileri olmasına rağmen revizyon gerekmediğini belirtmişlerdir. Tüm olgularda kansellöz allogreftlerin kullanıldığı seride, 22 olguda (\%69) radyolojik olarak defektin iyileştiğini belirtmişlerdir. ${ }^{[29]}$

Bingham ve ark., distraksiyon yöntemi ile tedavi ettikleri 31 hastada, iki yıllık süreçte $\% 87$ sağkalım bildirmişler, bir olguya aseptik gevşeme, bir olguya instabilite, bir olguya da derin enfeksiyon nedeni ile revizyon uygulamışlardır. Son takipte, bu üç hastada asetabular osteoentegrasyon izlenmediğini belirtmişler, hastaların Harris kalça skorlarında 43'ten 77'ye değişim gözlemişlerdir. En yaygın komplikasyon olarak da dört olguda kısmi siyatik felci görülmüştür. ${ }^{[30]}$

Yapılan çalışmalar, nispeten yeni olan bu tekniği değerlendirmek için daha uzun süre takipli ek serilere ihtiyaç olduğunu göstermektedir.

\section{"Cup-Cage Construct"}

"Highly porous acetabular" komponentlerdeki son yenilikler, gelişmiş biyolojik ve mekanik özellikler sunar. ${ }^{[8,29]} \mathrm{Bu}$ implantların bir yararı, kemiğe karşı

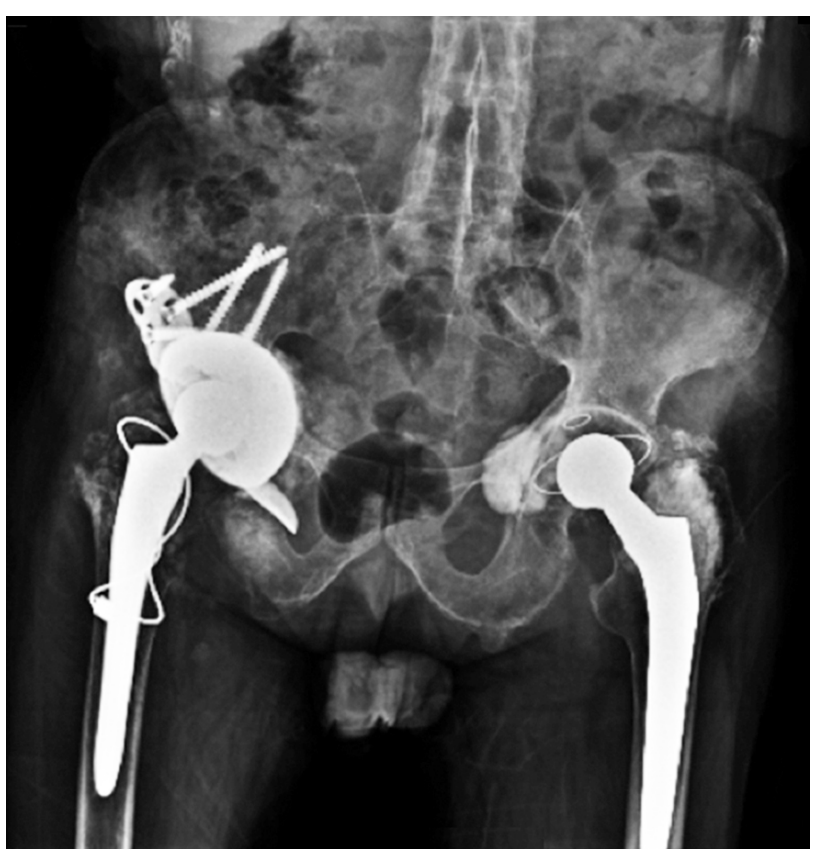

Şekil 2. Antero-posterior (ön-arka) pelvis grafisinde asetabular kafes ve allogreft uygulaması sonrası 4. yıl; implantın stabil olduğu ve vidaların çevresinde herhangi bir osteoliz olmadığı görülmekte.

yüksek bir sürtünme katsayısıdır. ${ }^{[31]}$ Ayrıca, bu implantların düşük sertliği stres korumasını en aza indirirken, fizyolojik yük transferini teşvik edebilir. Bu sayede, "highly porous acetabular" komponentler, daha önce radyoterapi tedavisi almış kemikler de dâhil olmak üzere, kemik kalitesi ve miktarının azaldığı pelvik devamsızlığın tedavisinde etkilidir. ${ }^{[8]}$

“Cup-cage” tekniği, çok gözenekli bir 'jumbo' asetabular bileşenin konak kemik üzerine yerleştirilmesini içerir. 'Jumbo' kap, kadınlarda 62 mm, erkeklerde ise $66 \mathrm{~mm}$ ölçülerinde olur. ${ }^{[32,33]}$ Gerekirse, kalan kemik defektlerini doldurmak için gözenekli metal takviyeler eklenebilir. Asetabular bileşenin üzerine, iliumdan iskiuma kadar olan defekti (devamsızlığı) kapsayan bir kafes yerleştirilir. Kafes, vidalarla veya bir yaka (flange) ile iskiuma alttan sabitlenebilir. Kap ve kafes, kafese yerleştirilen ve konakçı kemiğe uzanan bir vida ile birleştirilir (Şekil 2).

Kosashvili ve ark., 26 hastayı kapsayan serinin 23 olgusunda $(\% 88,5)$ klinik ve radyolojik başarılı sonuçlar bildirmişler, üç olguda $(\% 11,5)$ ise ameliyat sonrası birinci yılda migrasyon olduğunu, Harris kalça skoru ortalamasının 46,6'dan 76,6'ya yükseldiğini gözlemişler, iki olguda dislokasyon, bir olguda yüzeyel enfeksiyon ve bir olguda da kısmi peroneal sinir felci bildirmişlerdir. ${ }^{[34]}$ Benzer şekilde Konan ve ark., 
24 hastanın ortalama altı yıllık takibinde, ağrının azalması ve fonksiyonellik alanında olumlu sonuçlar gözlemişler, bir olguya derin enfeksiyon, üç olguya ise tekrarlayan instabilite sebebiyle revizyon uygulamışlardır.[35]

Rogers ve ark., "cup-cage" rekonstrüksiyon uyguladıkları 42 hastada \%9,5 revizyon oranı bildirmişler, iki olguda tekrarlayan instabilite, iki olguda ise rekonstrüksiyonun başarısızlığından dolayı revizyon yapmışlardır. ${ }^{[19]}$ Amenabar ve ark., 45 olguda, \%9 oranında aseptik gevşeme sebebiyle revizyon uygulamışlardır. ${ }^{[36]}$

Alfaro ve ark., kronik pelvik devamsızlığı olan beş olguda, son takip süresine kadar asetabulumun stabil kaldığını ve kalça rotasyon merkezinde başarılı düzelme olduğunu belirtmişlerdir. ${ }^{[37]}$ Benzer şekilde Martin ve ark., 27 hastalık serilerinde, beş yıl içinde hiçbir hastaya revizyon gerekmediğini ve asetabular komponent stabilitesinin iyi olduğunu belirtmişlerdir. Aynı çalışmada defektin iyileşme oranı \%74 olarak bildirilmiştir. ${ }^{[25]}$

\section{Triflange Komponentler}

Triflange kaplar özel olarak tasarlanmış, gözenekli ve/veya hidroksiapatit kaplı, iliak, iskial ve pubik yakalara (flange) sahip titanyum asetabular bileşenlerdir. ${ }^{[6]}$ Yakalar, kalça merkezini anatomik konumuna yakın bir yerde tutarken, stabilite için implant ile konakçı kemik arasında yakın temasa izin verir. Bu yapı, defektin iyileşmesini ve implantın biyolojik tespitini sağlar. Özel triflange bileşenlerinin önde gelen dezavantajları; operasyon öncesi tasarım ve üretim sürecinin göreceli karmaşıklığı ile maliyetidir.

Özel bir bileşen oluşturma süreci, metal çıkarma yazılımı kullanılarak, hastanın pelvisinin BT taramasıla başlatılır. Daha sonra, baş ve kap oryantasyonunu değerlendirmek için "3D" (üç boyutlu) model oluşturulur ve incelenir. ${ }^{[6]}$

Cerrahi teknik, bir kılavuz olarak özel "3D" modeli kullanarak triflange implantın optimum şekilde oturmasını sağlamak için, bir oyucu (burr) kullanarak çıkıntılı kemiğin hazırlanmasını içerir. Kemik grefti kullanılıyorsa, cerrah komponenti aşırı greft ile lateralize etmemeye özen göstermelidir. Özel triflange yapı, ilium üzerindeki abduktorların altında pelvise döndürülür. Triflange implant, iskium ve pubisin alt kemiğine (yani, kemiğin en zayıf ve parçalanmanın yaygın olduğu yere) sabitlenir. Ardından defekt azaltılır ve proksimal vidalar ilium içine yerleştirilir. Bu yapıda tipik olarak 9-13 vida kullanılır.

DeBoerve ark., allogreft (freeze-dried allograft) kullandıkları ve 20 hasta içeren serilerinde, 18 hastada köprü oluşturan kallus gözlemişler, pelvik devamsızlığın devam ettiği olgularda da, implant migrasyonu ve vida kııılması olmadığını belirtmişler, beş hastada ise ameliyat sonrası dönemde dislokasyon olduğunu ve hiçbir hastaya revizyon yapılmadığını bildirmişlerdir. On yıllık takipte $\% 90$ başarı oranı ile, bunun pelvik devamsızlık rekonstrüksiyonlarında tercih edilebilecek bir seçenek olduğunu belirtmişlerdir. ${ }^{[4]}$ Benzer şekilde Taunton ve ark., 57 hastalık serilerinde, triflange implantların pelvik devamsızlık tedavisindeki olumlu sonuçlarını belirterek, bunların orta vadede diğer tedavi yöntemlerine benzer maliyette olduğunu vurgulamışlardır. ${ }^{[6]}$

Holt ve Denis, masif peri-asetabular kemik kaybı (Paprosky Tip 3B) olan, triflange asetabular komponent ile rekonstrüksiyon uyguladıkları 26 hastanın 23 'ünde (\%88,5), kısa süreli takipte (ortalama 54 ay) başarılı sonuçlar elde etmişler, üç olguda iskial tespit kaybından dolayı başarısızlık gözlemişlerdir. Buna ilaveten, pelvik devamsızlığı olan olgularda triflange implanta ek olarak kolon plak tespiti yapılmasını önermişlerdir. ${ }^{[38]}$

Friedrich ve ark., 18 hastanın ortalama 30 aylık takibinde, asetabular komponentin radyolojik olarak stabil olduğunu ve iki olguda derin enfeksiyon, üç olguda da dislokasyon gözlemişlerdir. ${ }^{[39]}$ Benzer şekilde Matar ve ark., 17 hastalık serilerinde ortalama 3,6 yıllık takipte, tüm olguların radyolojik olarak stabil olduğunu belirtmişlerdir. Aynı çalışmada; bir olguda drenaj gerektiren hematom, bir olguda ameliyat sırasında ilium kırığı, diğer bir olguda ise tekrarlayan dislokasyon meydana geldiğini belirterek, \%17,6 komplikasyon oranı bildirmişlerdir. ${ }^{[40]}$

Wind ve ark., peri-asetabular defekti (Paprosky tip $3 \mathrm{~A} / 3 \mathrm{~B}$ ve AAOS tip III/IV) olan 19 hastayı özel yapım triflange asetabular komponent ile tedavi ederek, 31 aylık sonuçlarını yayımlamışlar; olguların \%65'ini başarılı kabul ettikleri bu çalışmada, hem hasta hem de cerrahın beklentilerinin gerçekçi olması gerektiğini belirtmişlerdir. ${ }^{[41]}$

Özel yapım triflange bileşenleri, kısa ve orta vadede umut verici sonuçlar göstermiştir. Özel yapım olmayan rekonstrüksiyon halkalarına ve kafeslerine değerli bir alternatif olarak görünmektedir. Bu sistemin en büyük dezavantajı, ameliyat öncesi şablonlama sürecinin karmaşıklı̆ıdır. Tasarım sürecinin tamamlanması birkaç hafta sürer ve cerrahın mühendisle yakın çalışmasını gerektirir. Bu konuda daha uzun süreli yeni çalışmalara ihtiyaç vardır.

\section{Metal Augmentler}

Pelvik devamsızlıkta rekonstüksiyon için diğer bir yöntem, 'jumbo' asetabular kap ile poröz metal augment implantasyonudur. Osteoentegrasyon ve kemik büyümesi, çimentosuz asetabular bileşenlerin uzun 

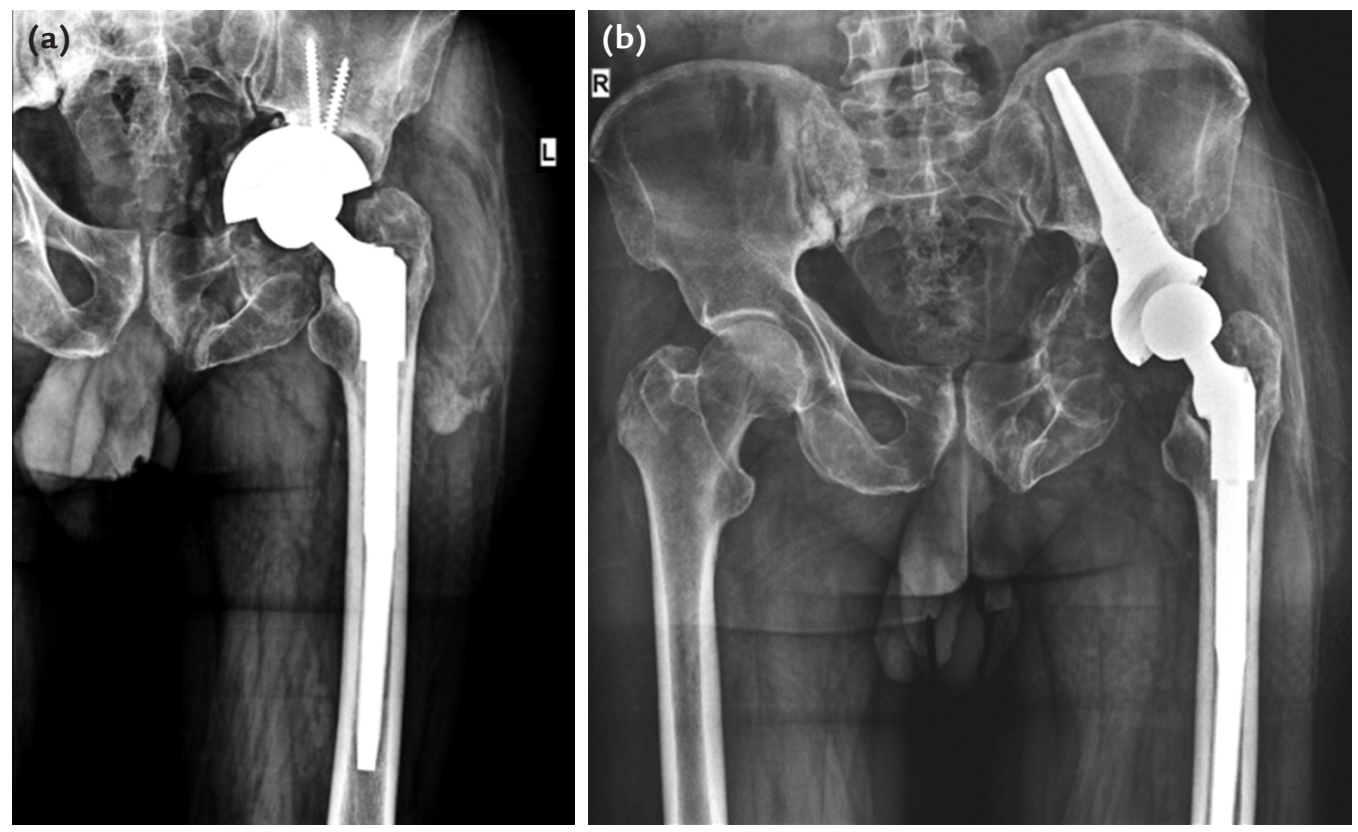

Şekil 3. a, b. Antero-posterior (ön-arka) sol kalça grafisinde asetabulumun pelvis içerisine doğru yer değiştirdiği ve pelvik devamlılığın bozulduğu görülmekte (a). Antero-posterior (ön-arka) pelvis grafisinde pedestal asetabular implant ile rekonstrüksiyon sonrası 3. yıl takip grafisinde implantın stabil olduğu görülmekte (b).

vadeli sağkalımı için çok önemlidir. Trabeküler metal implantlar, diğer yöntemlere göre daha düşük revizyon ve komplikasyon oranına sahiptir. ${ }^{[42]}$

Sporer ve Paprosky, pelvik devamsızlığı, augment kullanarak veya kullanmadan, trabeküler asetabular komponent ile stabilize etmişler; 13 hastanın ortalama 2,6 yıllık takibinde, bir hastada cerrahi gerektirmeyen radyografik gevşeme gözlemişler ve metal augment kullanarak ya da kullanmadan uygulanan trabeküler metal asetabular komponentin, kısa vadede güvenilir ve tekrarlanabilir sonuçlar vereceğini bildirmişlerdir. ${ }^{[5]}$

Batuyong ve ark., Paprosky tip 3 ve 4 defekti olan 24 hastada, tantalum asetabular implantlar kullanarak rekonstrüksiyon yapmışlar, septik gevşeme meydana gelen iki olgu dışında başarılı klinik ve radyolojik sonuçlar elde etmişlerdir (Şekil 3). ${ }^{[43]}$

\section{Komplikasyonlar}

Pelvik devamsızlığın tedavisinde halen kullanılan ve yeni gelişen birçok yönteme rağmen, bunların hiçbirinde, kemik defektinin restorasyonu, kısa ve uzun vadede implant başarısızlığı ve yüksek komplikasyon oranları gibi başlıca engeller tam olarak çözülememiştir. Literatürde \%25-\%80 oranında komplikasyon bildirilmektedir. ${ }^{[20,21,41]}$ En sık görülen komplikasyonlar; herhangi bir revizyon kalça artroplastisinde de görülebilen dislokasyon, sinir yaralanması ve enfeksiyondur. ${ }^{[22,23,44]}$

\section{Dislokasyon}

Pelvik devamsızlık varlığında, revizyon artroplasti ile ilişkili en yaygın komplikasyon dislokasyondur. Dislokasyon insidansı $\% 0^{[26]}$ ile $\% 40^{[21]}$ arasında değişmektedir. Yüksek dislokasyon insidansı; geçirilen cerrahi sayısı, kemik ve yumuşak doku defektleri, abduktor kol zayıflığı ve geniş yaklaşımlara bağlanabilir. Asetabular kap oryantasyonu, çıkı riskini etkileyen önemli bir faktördür. ${ }^{[45]}$

Yüksek dislokasyon oranı nedeniyle, bazı yazarlar kısıtlı liner kullanılmasını önermektedir. Bunlar; superior gluteal sinir yaralanması nedeniyle abduktor kol güçsüzlügü, proksimal femoral yetersizliği, büyük trokanter kaynamaması ya da tekrarlayan dislokasyon öyküsü olan olgulardır. ${ }^{[4,46,47]}$

\section{Sinir Hasarı}

İskial yakayı konumlandırırken, disseksiyon sırasında siyatik sinir yaralanabilir. Bundan dolayı, bazı yazarlar iskial yakayı iskiumun içine yerleştirmeyi tercih ederler. Siyatik sinir hasarının diğer sebepleri arasında; yanlış ekartör kullanımı, aşırı uzatma ve kapsamlı yumuşak doku disseksiyonu yer alır. ${ }^{[48]}$ Benzer şekilde, proksimal iliumun disseksiyonu sırasında, superior gluteal sinir de yaralanabilir. Bunun sonucunda, abduktor kol zayıflığı ve trendelenburg yürüyüşüü görülebilir. ${ }^{[49]}$ Meydana gelebilecek 
sinir yaralanmasının ameliyat sonrası yönetiminde, ameliyat öncesi ayrıntılı nörovasküler muayene çok önemlidir.

\section{Derin Enfeksiyon}

Genellikle implantın çıkarılmasını gerektiren derin enfeksiyonun $\% 0$ ile $\% 30$ arasında meydana geldiği bildirilmiştir. ${ }^{[21,22]}$ Artan ameliyat süresi, geniş doku disseksiyonu, tekrarlayan ameliyatlar ve medikal ek hastalıklar, bu enfeksiyonlara katkıda bulunur.

\section{KAYNAKLAR}

1. Berry DJ, Lewallen DG, Hanssen AD, Cabanela ME. Pelvic discontinuity in revision total hip arthroplasty. J Bone Joint Surg Am 1999;81(12):1692-702. Crossref

2. Mahoney CR, Garvin KL. Periprosthetic acetabular stress fracture causing pelvic discontinuity. 2002;25(1):83-5. Crossref

3. Paprosky W, Sporer S, O'Rourke MR. The treatment of pelvic discontinuity with acetabular cages. Clin Orthop Relat Res 2006;453:183-7. Crossref

4. DeBoer DK, Christie MJ, Brinson MF, Morrison JC. Revision total hip arthroplasty for pelvic discontinuity. J Bone Joint Surg Am 2007;89(4):835-40. Crossref

5. Sporer SM, Paprosky WG. Acetabular revision using a trabecular metal acetabular component for severe acetabular bone loss associated with a pelvic discontinuity. J Arthroplasty 2006;21(6):87-90. Crossref

6. Taunton MJ, Fehring TK, Edwards P, Bernasek T, Holt GE, Christie MJ. Pelvic discontinuity treated with custom triflange component: a reliable option. Clin Orthop Relat Res 2012;470(2):428-34. Crossref

7. Berry DJ. Identification and management of pelvic discontinuity; 2001;24(9):881-2. https://pubmed.ncbi.nlm. nih.gov/11570468/

8. Joglekar SB, Rose PS, Lewallen DG, Sim FH. Tantalum acetabular cups provide secure fixation in THA after pelvic irradiation at minimum 5-year followup. Clin Orthop Relat Res 2012;470(11):3041-7. Crossref

9. Kurtz S, Ong K, Lau E, Mowat F, Halpern M. Projections of primary and revision hip and knee arthroplasty in the United States from 2005 to 2030. J Bone Joint Surg Am 2007;89(4):780-5. Crossref

10. Iorio R, Robb WJ, Healy WL, Berry DJ, Hozack WJ, Kyle RF, Lewallen DG, Trousdale RT, Jiranek WA, Stamos VP, Parsley BS. Orthopaedic surgeon workforce and volume assessment for total hip and knee replacement in the United States: preparing for an epidemic. J Bone Joint Surg Am 2008;90(7):1598-605. Crossref

11. Ho K-T, Wong K-Y. Use of Structural Bone Graft for Reconstruction of Acetabular Defects in Primary Total Hip Arthroplasty: A 13-year Experience. J Orthop Trauma Rehabil 2016;20(1):30-4. Crossref

12. D’Antonio JA, Capello WN, Borden LS, Bargar WL, Bierbaum BF, Boettcher WG, Steinberg ME, Stulberg SD, Wedge $\mathrm{JH}$. Classification and management of acetabular abnormalities in total hip arthroplasty. Clin Orthop Relat Res 1989;(243):126-37. Crossref

13. Paprosky WG, Perona PG, Lawrence JM. Acetabular defect classification and surgical reconstruction in revision arthroplasty: a 6-year follow-up evaluation. J Arthroplasty 1994;9(1):33-44. Crossref
14. Schinsky MF, Della Valle CJ, Sporer SM, Paprosky WG. Perioperative testing for joint infection in patients undergoing revision total hip arthroplasty. J Bone Joint Surg Am 2008;90(9):1869-75. Crossref

15. Wendt MC, Adler MA, Trousdale RT, Mabry TM, Cabanela ME. Effectiveness of false profile radiographs in detection of pelvic discontinuity. J Arthroplasty 2012;27(7):1408-12. Crossref

16. Martin JR, Barrett IJ, Sierra RJ, Lewallen DG, Berry DJ. Preoperative radiographic evaluation of patients with pelvic discontinuity. J Arthroplasty 2016;31(5):1053-6. Crossref

17. Giori NJ, Sidky AO. Lateral and high-angle oblique radiographs of the pelvis aid in diagnosing pelvic discontinuity after total hip arthroplasty. J Arthroplasty 2011;26(1):110-2. Crossref

18. Ataç GK, İnal T. BT İncelemelerde Görüntü Kalitesi ve Artefaktlar. Türk Radyoloji Seminerleri 2020;8(1):110-28. Crossref

19. Rogers BA, Whittingham-Jones PM, Mitchell PA, Safir OA, Bircher MD, Gross AE. The reconstruction of periprosthetic pelvic discontinuity. J Arthroplasty 2012;27(8):1499-506.e1. Crossref

20. Sporer SM, O'Rourke M, Paprosky WG. The Treatment of Pelvic Discontinuity During Acetabular Revision. J Arthroplasty 2005;20:79-84. Crossref

21. Stiehl JB, Saluja R, Diener T. Reconstruction of major column defects and pelvic discontinuity in revision total hip arthroplasty. J Arthroplasty 2000;15(7):849-57. Crossref

22. Eggli S, Müller C, Ganz R. Revision surgery in pelvic discontinuity: an analysis of seven patients. Clin Orthop Relat Res 2002;398:136-45. Crossref

23. Goodman S, Saastamoinen $H$, Shasha $N$, Gross $A$. Complications of ilioischial reconstruction rings in revision total hip arthroplasty. J Arthroplasty 2004;19(4):436-46. Crossref

24. Springer BD, Berry DJ, Cabanela ME, Hanssen AD, Lewallen DG. Early postoperative transverse pelvic fracture: a new complication related to revision arthroplasty with an uncemented cup. J Bone Joint Surg Am 2005;87(12):262631. Crossref

25. Martin JR, Barrett I, Sierra RJ, Lewallen DG, Berry DJ. Construct rigidity: keystone for treating pelvic discontinuity. J Bone Joint Surg Am 2017;99(9):e43. Crossref

26. Sporer SM, Bottros JJ, Hulst JB, Kancherla VK, Moric M, Paprosky WG. Acetabular distraction: an alternative for severe defects with chronic pelvic discontinuity? Clin Orthop Relat Res 2012;470(11):3156-63. Crossref

27. Sheth NP, Melnic CM, Paprosky WG. Acetabular distraction: an alternative for severe acetabular bone loss and chronic pelvic discontinuity. Bone Joint J 2014;96-B(11_ Supple_A):36-42. Crossref

28. Brown NM, Hellman M, Haughom BH, Shah RP, Sporer SM, Paprosky WG. Acetabular distraction: an alternative approach to pelvic discontinuity in failed total hip replacement. Bone Joint J 2014;96-B(11_Supple_A):73-7. Crossref

29. Sheth NP, Melnic CM, Brown N, Sporer SM, Paprosky WG. Two-centre radiological survivorship of acetabular distraction technique for treatment of chronic pelvic discontinuity: mean five-year follow-up. Bone Joint J 2018;100-B(7):909-14. Crossref

30. Bingham JS, Arthur JR, Trousdale RT, Lewallen DG, Berry DJ, Abdel MP. Acetabular Distraction Technique for the Treatment of Chronic Pelvic Discontinuities: Excellent ShortTerm Implant Survivorship and Good Clinical Outcomes. J Arthroplasty 2020;35(10):2966-71. Crossref 
31. Meneghini RM, Meyer C, Buckley CA, Hanssen AD, Lewallen DG. Mechanical stability of novel highly porous metal acetabular components in revision total hip arthroplasty. J Arthroplasty 2010;25(3):337-41. Crossref

32. Von Roth P, Abdel MP, Harmsen WS, Berry DJ. Uncemented jumbo cups for revision total hip arthroplasty: a concise follow-up, at a mean of twenty years, of a previous report. J Bone Joint Surg Am 2015;97(4):284-7. Crossref

33. Whaley AL, Berry DJ, Harmsen WS. Extra-large uncemented hemispherical acetabular components for revision total hip arthroplasty. J Bone Joint Surg Am 2001;83(9):1352-7. Crossref

34. Kosashvili Y, Backstein D, Safir O, Lakstein D, Gross A. Acetabular revision using an anti-protrusion (ilio-ischial) cage and trabecular metal acetabular component for severe acetabular bone loss associated with pelvic discontinuity. J Bone Joint Surg Br 2009;91-B(7):870-6. Crossref

35. Konan S, Duncan CP, Masri BA, Garbuz DS. The cup-cage reconstruction for pelvic discontinuity has encouraging patient satisfaction and functional outcome at median 6-year follow-up. Hip Int 2017;27(5):509-13. Crossref

36. Amenabar T, Rahman WA, Hetaimish BM, Kuzyk PR, Safir $\mathrm{OA}$, Gross AE. Promising mid-term results with a cup-cage construct for large acetabular defects and pelvic discontinuity. Clin Orthop Relat Res 2016;474(2):408-14. Crossref

37. Alfaro JJB, Fernández JS. Trabecular Metal buttress augment and the Trabecular Metal cup-cage construct in revision hip arthroplasty for severe acetabular bone loss and pelvic discontinuity. Hip Int 2010;20(7_suppl):119-27. Crossref

38. Holt GE, Dennis DA. Use of custom triflanged acetabular components in revision total hip arthroplasty. Clin Orthop Relat Res 2004;429:209-14. Crossref

39. Friedrich MJ, Schmolders J, Michel RD, Randau TM, Wimmer MD, Kohlhof H, Wirtz DC, Gravius S. Management of severe periacetabular bone loss combined with pelvic discontinuity in revision hip arthroplasty. Int Orthop 2014;38(12):245561. Crossref
40. Matar HE, Selvaratnam V, Shah N, Jones HW. Custom triflange revision acetabular components for significant bone defects and pelvic discontinuity: early UK experience. J Orthop 2020;21:25-30. Crossref

41. Wind Jr MA, Swank ML, Sorger JI. Short-term results of a custom triflange acetabular component for massive acetabular bone loss in revision THA. Orthopedics 2013;36(3):e260-5. Crossref

42. Jain S, Grogan RJ, Giannoudis PV. Options for managing severe acetabular bone loss in revision hip arthroplasty. A systematic review. Hip Int 2014;24(2):109-22. Crossref

43. Batuyong ED, Brock HS, Thiruvengadam N, Maloney WJ, Goodman SB, Huddleston JI. Outcome of porous tantalum acetabular components for Paprosky type 3 and 4 acetabular defects. J Arthroplasty 2014;29(6):1318-22. Crossref

44. Christie MJ, Barrington SA, Brinson MF, Ruhling ME, DeBoer DK. Bridging massive acetabular defects with the triflange cup:2-to 9-year results. Clin Orthop Relat Res 2001;393:21627. Crossref

45. Elkins JM, Callaghan JJ, Brown TD. The 2014 Frank Stinchfield Award: The 'landing zone'for wear and stability in total hip arthroplasty is smaller than we thought: a computational analysis. Clin Orthop Relat Res 2015;473(2):441-52. Crossref

46. Su EP, Pellicci PM. The role of constrained liners in total hip arthroplasty. Clin Orthop Relat Res 2004;(420):122-9. Crossref

47. Williams J, Ragland P, Clarke S. Constrained components for the unstable hip following total hip arthroplasty: a literature review. Int Orthop 2007;31(3):273-7. Crossref

48. Mohler CG, Collis DK. Early complications and their management. In: Callaghan JJ, Rosenberg AG, Rubash HE, editors. The Adult Hip, Vol. II. Philadelphia: LippincottRaven; 1998. p.1125-47.

49. Jacobs LG, Buxton RA. The course of the superior gluteal nerve in the lateral approach to the hip. J Bone Joint Surg Am 1989;71(8):1239-43. https://pubmed.ncbi.nlm.nih. gov/2777853/ 